\title{
Social determinants of Self-Rated Health amony Polish women and men - results from the COURAGE in Europe project
}

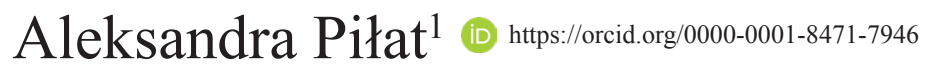 \\ Michał Wilga \\ Katarzyna Zawisza ${ }^{1}$ @ htpps///orid.orgy0000-0002-0934-7823
}

\begin{abstract}
${ }^{1}$ Department of Medical Sociology, Chair of Epidemiology and Preventive Medicine, Jagiellonian University Medical College, Kraków, Poland
\end{abstract}

Address for correspondence: Aleksandra Piłat, Kopernika 7a, 31-034 Kraków, +48 1242310 03, aleksandra.pilat@ uj.edu.pl

\section{Abstract}

The purpose of the paper is to identify and explore social determinants of health in women as compared to men. We used data from The Collaborative Research on Ageing in Europe (COURAGE in Europe) study. The study population consisted of 1,317 men and 1,921 women. The independent measure was Self-Rated Health (SRH) and the World Health Organisation Disability Assessment Schedule 2.0 (WHODAS 2.0), which incorporates both condition of health and disability. To find determinants of WHODAS 2.0. linear regression model was performed and in the case of SRH the proportional odds model was used. Analysis showed that women's SRH was significantly related to age, level of education. household income, type of occupation and family background. There was a similar relation observed amongst the male results. The analysis of the results indicates that socio-economic status is one of the main determinants of peoples' health. This relation was observed for both women and men. As analysis shows, the level of financial situation during childhood changes SRH especially among women. For men's health a more important variable was mother's occupation.

\section{Key words: determinants of health, Self-Rated Health, socio-economic status, Poland, WHODAS 2.0}

Stowa kluczowe: determinanty zdrowia, Polska, samoocena stanu zdrowia, status społeczno-ekonomiczny, WHODAS 2.0

\section{Introduction}

Self-Rated Health (SRH) is an important measure for epidemiological and socio-medical research that has been correlated with numerous aspects of social life, such as economic position, level of education, marital status or occupation [1].

Analysis of mortality rates and risk ratios of death during follow up among 170223 respondents aged
16 years and above in the Swedish Survey of Living Conditions 1975-1997, in relation to self rated health stated at the interview, by age, sex, socioeconomic group, chronic illness and over time.

There was a strong relation between poor self rated health and mortality, greater at younger ages, similar among men and women and among persons with and without a chronic illness. The relative relation between self rated health and subsequent death was stronger 
in higher than in lower socioeconomic groups, possibly because of the lower base mortality of these groups. However, the absolute mortality risk differences between persons reporting poor and good self rated health were similar across socioeconomic groups within each sex. The mortality risk difference between persons reporting poor and good self rated health was considerably higher among persons with a chronic illness than among persons without a chronic illness. The mortality risk among persons reporting poor health was increased for shorter $(<2$ years. It has been also observed, that SRH has a strong correlation with morbidity and mortality [2]. Further research has gone on to confirm that this correlation existed after controlling for co-founders such as age, gender, socio-economic status and objective health [3]. In this context it appears justified to suggest that the subjective health assessment could be even more sensitive in health monitoring than external measures of health [4]including sociodemographic, lifestyle, psychosocial, and physical variables, in association with self-rated health status using multivariate logistic regression models. A $p$-value $<0.05$ was considered to indicate statistical significance.

We found that negative psychosocial conditions, including frequent stress events and severe distress according to the psychosocial well-being index, were most strongly associated with poor self-rated health.

There are several theories trying to explain a powerful prediction about morbidity or/and mortality based on a person's own health assessment. The way in which a person evaluates their own health reveals their true well-being, which could not be examined by medical methods [5] one with seven (SRH-7. Despite SRH, as a measure of condition of health, has been challenged for the 'subjective approach' and for the personal factors such as, for example, hypochondria [6], it has still been recommended for health condition monitoring by World Health Organisation (WHO), the Centers for Disease Control and Prevention in the United States, and also by the European Union Commission [7]community-based cohort studies that reported (1.

SRH can be measured in various ways by using one simple questions or using scales. According to Eriksson et al. there could be three categories of using single question: non-comparative, age-comparative or timecomparative [5] one with seven (SRH-7. In this paper non-comparative SRH was used: people responded with their health status by answering a single-item question: in general how would you rate your health today. Another instrument for assessing health is developed by the WHO the World Health Organisation Disability Assessment Schedule 2.0 (WHODAS 2.0). This measure was based on the International Classification of Functioning, Disability and Health (ICF) used to evaluate the individual's function and disability [8]. WHODAS takes into account more than just the state of physical and psychological health. It is an instrument based on self-evaluation in everyday functioning across six domains: cognition, mobility, self-care, getting alone, life activities and participation in community activities. What is more, functional status might be an important determinant of SRH. The relationship between functional status and Self-Rated Health exist especially among older people [9].

Perception of good health among people, also in Poland, has been connected with better socio-economic position, being younger, being married and, furthermore, being male. Other factors related with a positive assessment of health include family background and being in employment. Our literature review shows that results from the other (usually Western) countries are generalized and transferred to a Polish social context. The few existing studies show that Poland has a unique situation. For instance, Poles assess their health as worse than other western European countries or the US [10-12] reducing inequalities in health and mortality has become a significant problem. The aim of the study was to evaluate the association between employment status and self rated health in study population.

The study was performed in the randomly selected population of individuals aged 25-64 years. Logistic regression was used to estimate odds ratios and $95 \%$ confidence intervals as well as to control the effects of employment status and self rated health.

The multifactorial logistic regression analysis indicates that, in men and women, self rated health was associated with employment status. Among unemployed men, the risk of low self health assessment was over 3 times higher than in the employed ones (adjusted $\mathrm{OR}=3.34 ; 95 \% \mathrm{Cl}: 1.96-11.58$ ). This is one of the reasons why it is so important to explore and understand the specific Polish context. It is necessary to adapt the delivery of health and social services to needs. This paper will focus on: the relationship between social determinants of women's health in comparison to men; showing relations in health according to age and social factors; and explaining the role of social determinants to people's physical and mental well-being.

The aim of this study is to identify and explore social determinants of health in women as compared to men.

\section{Data and methods}

This analysis was performed on cross-sectional data from The Collaborative Research on Ageing in Europe (COURAGE in Europe) study. COURAGE in Europe was a 3-year project involving 12 partners from four European countries and the World Health Organisation. The field study was conducted by partners in Finland, Poland and Spain, where the survey has been administered to a sample of 10,800 persons, which was completed in March 2012. Fieldwork in Poland included a total of 4071 respondents. For the purposes of this study, the results obtained in Poland were taken into account. Due to missing data 3238 persons were taken into account. The sample consisted of 1,317 men and 1,921 women aged 18 years or older from Poland [13]. Participants were interviewed face-to-face in their own homes, with Computer-Assisted Personal Interviewing (CAPI).The present study was approved by the Bioethical Committee. 


\section{Measures}

Health was measured by using the World Health Organisation Disability Assessment Schedule 2.0 (WHODAS 2.0), which incorporates condition of health, and disability. Domains included in WHODAS 2.0 are: cognition, mobility, self-care, getting along, life activities, and participation [14]. These domains comprise the following items: In the past 30 days, how much difficulty did you have in: Standing for long periods such as 30 minutes? Taking care of your household responsibilities? Learning a new task, for example, learning how to get to a new place? How much of a problem did you have joining in community activities in the same way as anyone else can? How much have you been emotionally affected by your health problems? Concentrating on doing something for ten minutes? Walking a long distance such as a kilometre? Washing your whole body? Getting dressed? Dealing with people you do not know? Maintaining a friendship? Your day-today work?, which are assessed on a 5-point Likert scale $(1=$ none; $2=$ mild; $3=$ moderate; $4=$ severe; $5=$ extreme or cannot do). Total score ranged from 0 (least difficulty) to 100 (most difficulty), and high scores indicated a high level of disability. Self-Rated Health is elicited by the question In general how would you rate your health today? The answer is also assessed on a 5 point scale from the best (very good $=1$ ) to the worst (very bad $=5$ ).

Demographic issue such as sex, age (continuous variable), residence (rural/urban), and marital status were asked at the initial part of the interview. For the purposes of this analysis, variable marital status was grouped into married/cohabitating vs. never married vs. divorced/ separated/widowed.

Level of education and household income were independent variables used here as categorical measures of socio-economic status. For education, individuals were assigned an educational ranking that was either: primary or lower, vocational, high school, tertiary education or higher. Household income was divided into quintiles, where quintile one represented the poorest wealth quintile and quintile five the richest.

The occupation variable was based on ISCO-08. For the purposes of this analysis the generalized classification level (ISCO-0) was provided. It consists from three categories:

- White collar-worker (categories 1 Managers +2 Professionals +3 Technicians and associate professionals +4 Clerical support workers).

- Service industry (category 5 Service and sales workers).

- Manual labour (categories 6 Skilled agricultural, forestry and fishery workers $+7 \mathrm{Craft}$ and related trades workers +8 Plant and machine operators, and assemblers +9 Elementary occupations).

In result, occupation categories were: white-collar worker, service-industries worker, manual labour and additionally being retired/on disabled pension and the unemployed.
Two independent variables measure family background were: parents' financial situation in respondents' childhood (very good, good, moderate, bad, very bad) and parental occupation also based on ISCO-08 classification (white collar-worker, service industry, manual labour, unemployed/no mother/no father).

\section{Statistical analysis}

The linear regression model was created for each gender separately. The dependent variable was the result of 12 WHODAS 2.0, while the independent variables were:

- the area of residence (village, city);

- age (on the scale quotient);

- marital status;

- respondent's occupational categories;

- financial situation in childhood;

- occupational categories of the respondent's father and mother (social background);

- education and household income (socio-economic status).

Additionally to WHODAS 2.0. the subjective selfreporting level-of-health was taken into account. For the analysis of self-assessed health a proportional-odds model was used. The link function of that model was:

$$
\log \left(\frac{z_{j}}{1-z_{j}}\right)=\alpha_{j}-\beta x
$$

Where $z_{j}$ is cumulative probability (the sum of the probabilities category below the $\mathrm{y}-$ point division), $\alpha_{j}$ is the $\mathrm{j}$-th intercept (intercept for the $\mathrm{j}$-th model), $\beta$-is the vector of parameters, and $x$ is a matrix of independent variables. The odds ratio determined lower self-assessed health status in relation to the reference category. In the second model the same independents variables were included as in the first model.

Variables such as age and WHODAS 2.0. were not normal, therefore, non-parametric U Mann-Whitney's tests were used in the statistical analyses. For others variables $\chi^{2}$ test were used. To find determinants of WHODAS 2.0. linear regression model was used. In case of SRH the proportional odds model was used. All statistical analyses were performed using R 3.2.0 software with the stats and MASS extension packages.

\section{Results}

The characteristic of the respondents separately for each gender is shown in Table I. More than a half of the overall sample $(59,2 \%)$ was female; a characteristic which is only to be expected in the ageing population. The mean age of the men was $58.24(S D=16.68)$ years and for women it was $57.91(S D=16.67)$ years. The sample included more separated/widowed women, a status which is associated with excess mortality. 


\begin{tabular}{|l|c|c|c|}
\hline & $\begin{array}{c}\text { Male } \\
(\boldsymbol{n}=\mathbf{1 , 3 1 7})\end{array}$ & $\begin{array}{c}\text { Female } \\
(\boldsymbol{n}=\mathbf{1 , 9 2 1})\end{array}$ & $\boldsymbol{p}$ \\
\hline Age, mean $(S D)$ & $58.42(16.68)$ & $58.17(16.56)$ & $0.477^{\mathrm{b}}$ \\
\hline Urban/rural residence (\%) \\
\cline { 1 - 2 } Urban, & 53.5 & 58.4 & \multirow{2}{|l}{$\mathbf{0 . 0 0 6}^{\mathrm{a}}$} \\
\cline { 1 - 2 } Rural & 46.5 & 41.6 &
\end{tabular}

Marital status (\%)

\begin{tabular}{|c|c|c|c|}
\hline Married/cohabiting, & 66.1 & 50.9 & \\
\hline Never married & 18.1 & 12.7 & $<\mathbf{0 . 0 0 1}^{\mathrm{a}}$ \\
\hline Separate/widowed & 15.7 & 36.4 & \\
\hline
\end{tabular}

\begin{tabular}{|c|c|c|c|}
\hline \multicolumn{4}{|l|}{ Education (\%) } \\
\hline Primary school or lower & 20.8 & 26.0 & \multirow{4}{*}{$<0.001^{\mathrm{a}}$} \\
\hline Vocational school & 34.8 & 20.2 & \\
\hline High school completed & 26.7 & 30.9 & \\
\hline $\begin{array}{l}\text { Tertiary education or } \\
\text { higher }\end{array}$ & 17.7 & 22.9 & \\
\hline
\end{tabular}

Household income (\%)

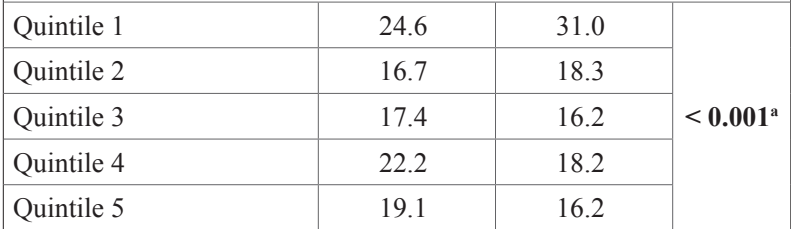

\section{Occupation (\%)}

\begin{tabular}{|c|c|c|c|}
\hline White-collar worker & 17.1 & 26.3 & \multirow{5}{*}{$<0.001^{\mathrm{a}}$} \\
\hline Service industries & 5.8 & 12.3 & \\
\hline Manual labour & 37.4 & 17.7 & \\
\hline Retired & 38.9 & 42.4 & \\
\hline Unemployed & 0.8 & 1.1 & \\
\hline
\end{tabular}

Parents' financial situation in childhood (\%)

\begin{tabular}{|l|r|r|r|}
\hline Very good & 4.6 & 5.3 & \\
\cline { 1 - 3 } Good & 25.6 & 28.8 & \\
\cline { 1 - 3 } Normal & 49.6 & 47.5 & \multirow{2}{*}{$\mathbf{0 . 1 2 5}^{\mathbf{a}}$} \\
\cline { 1 - 3 } Bad & 16.6 & 14.4 & \\
\cline { 1 - 3 } Very bad & 3.7 & 4.0 & \\
\cline { 1 - 3 } & & & \\
\cline { 1 - 3 } & &
\end{tabular}

\section{Father's occupation (\%)}

\begin{tabular}{|l|r|r|r|}
\hline White collar-worker & 14.4 & 14.9 & \multirow{2}{*}{$\mathbf{0 . 3}^{\mathrm{a}}$} \\
\cline { 1 - 3 } Service industry & 2.7 & 2.9 & \\
\cline { 1 - 2 } Manual labour & 81.4 & 79.6 & \\
\cline { 1 - 2 } Unemployed/no father & 1.6 & 2.5 & \\
\cline { 1 - 2 } & &
\end{tabular}

\section{Mother's occupation (\%)}

\begin{tabular}{|l|r|r|r|}
\hline White collar-worker & 12.8 & 13.1 & \\
\cline { 1 - 3 } Service industry & 5.8 & 6.4 & \multirow{2}{*}{$\mathbf{0 . 8 7 4}^{\mathrm{a}}$} \\
\cline { 1 - 2 } Manual labour & 43.7 & 43.9 & \\
\cline { 1 - 2 } Unemployed/no mother & 37.7 & 36.6 &
\end{tabular}

\section{Self-Rated Health (\%)}

\begin{tabular}{|l|c|c|c|}
\hline Very good & 11.2 & 7.7 & \multirow{2}{*}{} \\
\cline { 1 - 3 } Good & 32.0 & 34.5 & \multirow{2}{*}{$\mathbf{0 . 0 1 6}^{\mathbf{a}}$} \\
\cline { 1 - 3 } Moderate & 39.0 & 40.0 & \\
\cline { 1 - 3 } Bad & 15.0 & 15.0 & \\
\cline { 1 - 3 } Very bad & 2.9 & 2.8 & \\
\cline { 1 - 3 } WHODAS 2.0, Mean & $16.3(20,22)$ & $18.1(21,1)$ & $\mathbf{0 . 0 0 2}^{\mathbf{b}}$ \\
\hline
\end{tabular}

${ }^{\mathrm{a}} \chi^{2}$ test was used

${ }^{\mathrm{b}}$ U Mann-Whitney's test was used

Table I. Characteristic sample.

Source: Own study.
The research result shown a difference between gender according to level of education. Generally, women in Poland are better educated than men. The majority of women completed high school, tertiary education or higher. More than a third of males only finished secondary school which, compared to women, constitutes a very large group. In terms of the working sample, there was a preponderance of manual labour among men group and white-collar workers among women. Such a gender distribution in the labour market was consistent with the situation in the Polish labour market.

In the analysis residence locality was taken into account, and showed answer that the residence distributions of respondents residence were different.

The distribution of health score in WHODAS 2.0. was different for women and for men. Health score in WHODAS 2.0. for women was worse than for men. According to Self-Rated Health there were no importance difference between women and men. These two measures were explained below. The demographic and socio-economic characteristic of the study sample were shown in Table I. Table II shown linear regression between social factors and WHODAS 2.0. Table III shown odds ratio for worse self-reported health.

\section{Demographic characteristic and health}

As an analysis shown health scores grow with increasing age, for both gender. The linear regression model demonstrated a linear relationship between health and age - with every single year, health became worse. Similar relationship between variables was observed in the proportional odds model. Lower Self-Rated Health status in relation to the increasing age was observed.

Women who were married had significantly worse health than those who had never been married. This was the opposite to most research conducted in Europe and the USA, which usually demonstrated the protective impact of marriage for men rather than for women. The estimates from the odds ratio did not confirm any correlation between marriage and health. This was also true of residence area, where no statistical difference observed.

\section{Socio-economic characteristics and health}

Models confirmed a strong correlation between health and socio-economic status, both for women and men. Taking into account the components such as education level and household income, the analysis shown education-related and income-related relative inequalities. Those who completed vocational school, compared with primary school or lower, more frequently reported better health. Nevertheless, parameter values were similar between high school on the one hand and college or higher on the other. It may be caused by the fact that achieving a vocational level of education is sufficient to change lifestyles and everything connected to them.

Health correlated with household income for both women and men. The only difference between them was on the second quintile which is insignificant for men. 


\begin{tabular}{|c|c|c|c|c|c|c|c|c|c|}
\hline \multirow{3}{*}{$\begin{array}{ll} & \text { Variable } \\
\text { Age } & \\
\end{array}$} & \multirow{3}{*}{ Category } & \multicolumn{4}{|c|}{ Men $-\mathbf{R 2}=\mathbf{0 . 3 2}$} & \multicolumn{4}{|c|}{ Women $-\mathrm{R} 2=0.343$} \\
\hline & & \multirow{2}{*}{$\begin{array}{l}\boldsymbol{\beta} \\
0.47\end{array}$} & \multicolumn{2}{|c|}{$95 \%$ CI for $\beta$} & \multirow{2}{*}{$\begin{array}{c}\boldsymbol{p} \\
<0.001 \\
\end{array}$} & \multirow{2}{*}{$\begin{array}{l}\boldsymbol{\beta} \\
0.56 \\
\end{array}$} & \multicolumn{2}{|c|}{$95 \%$ CI for $\beta$} & \multirow{2}{*}{$\begin{array}{c}p \\
<0.001\end{array}$} \\
\hline & & & 0.38 & 0.55 & & & 0.48 & 0.63 & \\
\hline \multirow[t]{2}{*}{ Urban/rural residence } & Rural (ref.) & 0 & & & & 0 & & & \\
\hline & Urban & 1.28 & -0.65 & 3.21 & 0.193 & 1.17 & -0.46 & 2.8 & 0.159 \\
\hline \multirow[t]{3}{*}{ Marital status } & Never married (ref.) & 0 & & & & 0 & & & \\
\hline & Married & -1.45 & -4.13 & 1.22 & 0.287 & -3.79 & -6.34 & -1.24 & 0.004 \\
\hline & Widow/separate & 2.12 & -1.35 & 5.6 & 0.230 & -0.34 & -3.17 & 2.49 & 0.813 \\
\hline \multirow[t]{4}{*}{ Education } & Primary school or lower (ref.) & 0 & & & & 0 & & & \\
\hline & Vocational school & -10.09 & -12.76 & -7.42 & $<0.001$ & -5.83 & -8.3 & -3.37 & $<0.001$ \\
\hline & High school & -12.94 & -15.88 & -10 & $<0.001$ & -8.69 & -11.08 & -6.3 & $<0.001$ \\
\hline & College or higher & -12.37 & -16.02 & -8.71 & $<0.001$ & -7.96 & -10.87 & -5.04 & $<0.001$ \\
\hline \multirow[t]{5}{*}{ Household income } & Quintile 1 (ref.) & 0 & & & & 0 & & & \\
\hline & Quintile 2 & -1.59 & -4.54 & 1.35 & 0.288 & -4.08 & -6.37 & -1.79 & $<0.001$ \\
\hline & Quintile 3 & -5.51 & -8.47 & -2.56 & $<0.001$ & -3.55 & -6 & -1.1 & 0.005 \\
\hline & Quintile 4 & -3.98 & -6.8 & -1.15 & 0.006 & -5.11 & -7.54 & -2.68 & $<0.001$ \\
\hline & Quintile 5 & -6.88 & -9.92 & -3.85 & $<0.001$ & -2.94 & -5.6 & -0.28 & 0.03 \\
\hline \multirow[t]{5}{*}{ Occupation } & White collar-worker (ref.) & 0 & & & & 0 & & & \\
\hline & Service industry & 1.89 & -2.61 & 6.38 & 0.411 & 3.55 & 0.69 & 6.41 & 0.015 \\
\hline & Manual labour & 1.88 & -1.25 & 5.02 & 0.238 & -0.36 & -3.17 & 2.44 & 0.799 \\
\hline & Retired/disabled pension & 0.81 & -2.58 & 4.2 & 0.64 & -2.22 & -4.74 & 0.3 & 0.084 \\
\hline & Unemployed & 2.88 & -8.03 & 13.79 & 0.605 & -3.07 & -10.49 & 4.35 & 0.417 \\
\hline \multirow{5}{*}{$\begin{array}{l}\text { Parents' financial situation } \\
\text { in childhood }\end{array}$} & Very good (ref.) & 0 & & & & 0 & & & \\
\hline & Good & -2.96 & -7.63 & 1.72 & 0.215 & -1.24 & -4.92 & 2.43 & 0.507 \\
\hline & Norma & -3.84 & -8.4 & 0.72 & 0.099 & 1.81 & -1.79 & 5.42 & 0.324 \\
\hline & $\mathrm{Bad}$ & -0.72 & -5.74 & 4.3 & 0.779 & 4.62 & 0.54 & 8.7 & 0.027 \\
\hline & Very bad & 7.63 & 1.03 & 14.23 & 0.024 & 10.38 & 5.12 & 15.64 & $<0.001$ \\
\hline \multirow[t]{4}{*}{ Father's occupation } & White collar-worker (ref.) & 0 & & & & 0 & & & \\
\hline & Services & 2.37 & -3.87 & 8.62 & 0.456 & 4.91 & -0.14 & 9.96 & 0.057 \\
\hline & Manual labour & -0.21 & -3.18 & 2.76 & 0.891 & 1.65 & -0.78 & 4.07 & 0.183 \\
\hline & Unemployed/no father & 0.44 & -7.5 & 8.38 & 0.913 & 3.57 & -1.83 & 8.96 & 0.195 \\
\hline \multirow[t]{4}{*}{ Mother's occupation } & White-collar worker (ref.) & 0 & & & & 0 & & & \\
\hline & Services & -1.2 & -5.93 & 3.53 & 0.619 & -1.91 & -5.76 & 1.93 & 0.33 \\
\hline & Manual labour & -4.09 & -7.67 & -0.52 & 0.024 & -3.77 & -6.62 & -0.91 & 0.010 \\
\hline & Unemployed/no mother & -3.83 & -7.37 & -0.3 & 0.033 & -1.8 & -4.66 & 1.06 & 0.217 \\
\hline
\end{tabular}

Note: $r e f=$ reference category.

Table II. Linear regression analysis for the prediction of variance in health dimensions scores by socio-demographics variables.

Source: Own study.

This led to the conclusion about the strong relationship between socio-economic status and health. Regarding to analysis, people with lower socio-economic status, regardless of gender, had the poorest health and they had more chance of becoming disabled. The fact that socioeconomic status was important for health also supports the odds ratio model of self-reported health.

The odds ratio determined the probability of poorest self-reported health in relation to the reference category, which was in that case a relative lack of education/primary education; and in case of income the lowest income (quintile 1). Higher-educated people enjoyed better self-reported health. Men with secondary education felt better than men with at most primary school. Educated to high school level were $46 \%$ less likely to report poor health than people with primary school or lack of education. Education to tertiary level also reduced the chance of poor health. Education was also an important factor in the case of women. Women with the highest education level, as well as men, had a greater chance for better health than women and men with primary school or lower.

In the study, different kinds of occupation were taken into account. WHODAS 2.0. and Self-Rated Health was analysed in the relationship to occupations, such as manual labour, white-collar worker, service industries worker, being retired/ on a disability pension and 


\begin{tabular}{|c|c|c|c|c|c|c|c|c|c|}
\hline \multirow{3}{*}{$\begin{array}{l}\text { Variable } \\
\text { Age }\end{array}$} & \multirow{3}{*}{ Category } & \multicolumn{4}{|c|}{ Men - R2 Nagelkerke $=\mathbf{0 . 3 5 3}$} & \multicolumn{4}{|c|}{ Women - R2 Nagelkerke $=0.378$} \\
\hline & & \multirow{2}{*}{$\begin{array}{l}\text { OR } \\
1.06\end{array}$} & \multicolumn{2}{|c|}{$95 \%$ CI for OR } & \multirow{2}{*}{$\begin{array}{c}p \\
<0.001\end{array}$} & \multirow{2}{*}{$\begin{array}{l}\text { OR } \\
1.05\end{array}$} & \multicolumn{2}{|c|}{$95 \%$ CI for OR } & \multirow{2}{*}{$\begin{array}{c}\boldsymbol{p} \\
<0.001\end{array}$} \\
\hline & & & 1.05 & 1.07 & & & 1.04 & 1.06 & \\
\hline \multirow[t]{2}{*}{ Urban/rural residence } & Rural (ref.) & 1 & & & & 1 & & & \\
\hline & Urban & 0.97 & 0.78 & 1.2 & 0.765 & 0.92 & 0.77 & 1.11 & 0.387 \\
\hline \multirow[t]{3}{*}{ Marital status } & Never married (ref.) & 1 & & & & 1 & & & \\
\hline & Married & 1.19 & 0.88 & 1.6 & 0.269 & 1.09 & 0.81 & 1.45 & 0.579 \\
\hline & Widow/separate & 1.14 & 0.77 & 1.68 & 0.52 & 1.23 & 0.89 & 1.69 & 0.208 \\
\hline \multirow[t]{4}{*}{ Education } & Primary school or lower (ref.) & 1 & & & & 1 & & & \\
\hline & Vocational school & 0.57 & 0.42 & 0.77 & $<0.001$ & 0.78 & 0.59 & 1.03 & 0.085 \\
\hline & High school & 0.53 & 0.38 & 0.74 & $<0.001$ & 0.54 & 0.41 & 0.7 & $<0.001$ \\
\hline & College or higher & 0.36 & 0.24 & 0.55 & $<0.001$ & 0.43 & 0.31 & 0.59 & $<0.001$ \\
\hline \multirow[t]{5}{*}{ Household income } & Quintile 1 (ref.) & 1 & & & & 1 & & & \\
\hline & Quintile 2 & 0.82 & 0.59 & 1.15 & 0.251 & 0.78 & 0.61 & 1.01 & 0.062 \\
\hline & Quintile 3 & 0.68 & 0.49 & 0.95 & 0.023 & 0.7 & 0.53 & 0.92 & 0.01 \\
\hline & Quintile 4 & 0.58 & 0.42 & 0.79 & $<0.001$ & 0.63 & 0.48 & 0.83 & $<0.001$ \\
\hline & Quintile 5 & 0.53 & 0.37 & 0.74 & $<0.001$ & 0.65 & 0.49 & 0.88 & 0.005 \\
\hline \multirow[t]{5}{*}{ Occupation } & White collar-worker (ref.) & 1 & & & & 1 & & & \\
\hline & Services industry & 2.12 & 1.28 & 3.52 & 0.003 & 1.27 & 0.92 & 1.76 & 0.15 \\
\hline & Manual labour & 1.75 & 1.22 & 2.51 & 0.002 & 1.75 & 1.27 & 2.39 & $<0.001$ \\
\hline & Retired/pensioner & 1.23 & 0.83 & 1.82 & 0.297 & 1.53 & 1.15 & 2.03 & 0.003 \\
\hline & Unemployed & 2.76 & 0.87 & 8.81 & 0.085 & 1.43 & 0.61 & 3.37 & 0.411 \\
\hline \multirow{5}{*}{$\begin{array}{l}\text { Parents' financial situation } \\
\text { in childhood }\end{array}$} & Very good (ref.) & 1 & & & & 1 & & & \\
\hline & Good & 0.71 & 0.4 & 1.27 & 0.247 & 1.52 & 0.99 & 2.32 & 0.054 \\
\hline & Norma & 0.95 & 0.55 & 1.67 & 0.871 & 2.53 & 1.67 & 3.85 & $<0.001$ \\
\hline & Bad & 1.43 & 0.78 & 2.63 & 0.247 & 3.63 & 2.27 & 5.81 & $<0.001$ \\
\hline & Very bad & 3.86 & 1.74 & 8.58 & $<0.001$ & 4.93 & 2.68 & 9.08 & $<0.001$ \\
\hline \multirow[t]{4}{*}{ Father's occupation } & White collar-worker (ref.) & 1 & & & & 1 & & & \\
\hline & Services & 0.82 & 0.4 & 1.69 & 0.593 & 1.31 & 0.74 & 2.33 & 0.349 \\
\hline & Manual labour & 0.97 & 0.69 & 1.37 & 0.854 & 1.08 & 0.83 & 1.42 & 0.563 \\
\hline & Unemployed/no father & 1.61 & 0.64 & 4.07 & 0.313 & 1.89 & 1.01 & 3.53 & 0.046 \\
\hline \multirow[t]{4}{*}{ Mother's occupation } & White collar-worker (ref.) & 1 & & & & 1 & & & \\
\hline & Services & 0.78 & 0.45 & 1.36 & 0.378 & 1.2 & 0.78 & 1.85 & 0.413 \\
\hline & Manual labour & 0.75 & 0.5 & 1.13 & 0.169 & 1.16 & 0.84 & 1.61 & 0.356 \\
\hline & Unemployed/no mother & 0.73 & 0.49 & 1.1 & 0.131 & 1.19 & 0.86 & 1.65 & 0.286 \\
\hline
\end{tabular}

Table III. The odds ratio model of self-reported health.

Source: Own study.

unemployed. The reference category was white-collar workers. Results from model of linear regression analysis for the prediction of variance in health dimensions scores by socio-demographic variables shown that women who were working in service sector have higher score in WHODAS 2.0., which means, that their health was worse in relation to white-collar workers. This relation was not observed in the self-rated model. More relevant data was shown in the odds ratio model. Men who were working in the services sector and as manual labour declared poorer health than white-collar workers. The chance on worse Self-Rated Health also increases in women who worked physically and among women who were retired or on a disability pension.

\section{Family backgyound}

There was a significant relation between both men's and women's health and mother's occupation. Better health was more prevalent in the group of men and women whose mother worked manually, relative to reference category. There was a relation between good health in men and the fact that their mother was unemployed. Among women whose father did not work during their childhood, the chance of poorer self-reported health increased, it was being strictly associated with the child's parents' financial situation - the worse the financial situation, the higher the likelihood of selfdeclaring poor health. 
The same tendency was observed in the second model of self-reported health. The odds ratio model shown that worst, bad or normal financial situation in childhood was correlated with worse health.

\section{Discussion}

Analysis is based on gender comparison and key social factors which are relevant to health assessment in two measures: SRH and WHODAS 2.0. There are well-known social determinants which are connected with health including: gender [15], age [16, 17], marriage [18], socio-economic status [17, 19]. Analysis also included factors such as family background, including parents' occupation and financial situation during respondents' childhood. The results demonstrate gender differences in Self-Rated Health and health conditions in relation to social determinants.

Women reported higher rates of poor SRH and lower rates of very good or good SRH, as compared with men. The similar pattern was observed with regard to reported health condition. Women are more likely to report more functional limitations and disability than men. Results in this study are comparable with the results of previous researches in other countries [17, 20]. While this pattern is quiet stable, many studies suggest that this difference has declined in recent years. What is more, previous study performed in Poland found no differences between women and men in their self-assessment of health [21].

The main trend in almost every developed country is population ageing. These trend is particularly important due to the condition of population health, because along with age there is a higher probability of physical and (or) psychological disability. Although people in their third age become more active than in past generations and their health condition is improving, nevertheless research demonstrate a correlation between health and age. Several studies have shown that ageing was associated with poor Self-Rated Health [22]. One of them was the longitudinal study conducted in Poland which demonstrate that SRH significantly declined during 12 year period [21]. Nevertheless, most of research have focused only on elderly or showing difference in health status between age groups. In this study, age was treated as a continuous variable which allowed to observe that SRH as well as WHODAS 2.0 become worse with every single year both for women and men.

A review of the existing literature on marital status and health condition highlighted that health outcome for married persons are better than for unmarried persons [23]. What is more, the benefits of marriage are not equal between women and men. The positive association is greater for men than women and is explained by the lesser risk of social isolation, a healthier lifestyle and the woman's family role in making emotional connections. Nevertheless, the result from Polish research does not confirm the relationship between marital status and health. The specific Polish situation is also established by cross-sectional study conducted in 2009 by the Polish
Central Statistical Office, which demonstrated similar relation. Almost $83 \%$ of people who have never been married indicate very good and good self-reported health. At the same time, $58.3 \%$ of married people had positive opinion about their health. Additionally, in the Central Statistical Offices' study there is no analysis describing marital status, gender and health relation of the respondents. This is an informational gap, which should be filled. The results obtained could be interpreted by social changes in the marital and family sphere which are bound up with transition from the traditional family to the post-modern family. This change set women free from their attachment to the home and allows them to take paid work; but at the same time, the change did not set them free from their traditional domestic duties. The achievement of women is gained at on expense they pay for their emancipation. Working double full time, women are paying for this in terms of their health, a tendency that is most evident in later adulthood. Additionally, civilizational change provokes women to emulate males' risky behaviours. The literature has shown the relation between risky behaviours and higher mortality rates [24-26]. One can assume that the poorer health of women can also be explained by their new, risky lifestyle (smoking, drinking etc.).

$\mathrm{SRH}$ is commonly used as an outcome measure in research on socio-economic inequalities in health. Level of educational attainment and income are very important social factors that determine not only social status, but also the individual's attitude to health and disease. Dowd and Zajacova showed the direct positive effect of education level on health condition. They found large differences in the predictive power of SRH by education and income: for people with higher income and/or higher education self-evaluation of health increased and mortality decreased [27]. Our study confirmed the positive relation between higher socio-economic status and better health and the results correspond with other studies showing that level of education and household income have a huge role according to SRH.

The health condition of privileged groups tends to be better and more consistent, which also can be clearly observed in the Social Diagnosis (2000-2015 Objective and Subjective Quality of Life in Poland). In every year of survey (2000, 2003, 2005, 2007, 2009, 2011, 2013 and 2015) Poles was asked about their health satisfaction. As the results show, the distribution of responses does not change across the years. There is a preponderance of people with primary and lower education among people who are not satisfied with their health and at the same time a lower distribution among "dissatisfied and very dissatisfied" of respondents with a higher education (www.diagnoza.com).

This findings could be interpreted by the fact, that socio-economic status directly affects living conditions, compliance with hygiene, nutrition and is significantly reflected in an individual's health. What is more, it is proven that better health among those who have completed a certain stage of education is associated with greater body awareness, better and healthier diet and 
medical knowledge at a higher level. Alvarez-Galvez et al. compared three socio-economic determinants of health (income, education and occupational status) in the European countries for the period 2002-2008. The analysis showed that despite the differences between the countries higher level of education was related with a good general state of health and we arrived to the same conclusion [28]. It could be associated with the fact that level of education was one of the most stable attribute in adult life whereas household income or type of occupation can vary with time. The powerful correlation between level of education and SRH could be also seen in the forecasts of life expectancy in Poland - 30 year old men with lesser education (vocational) are likely to live 66.5 years (at the time of the study). To compare, the same group of men, but with a higher education, are likely to live over 12 years longer. For women, the difference is smaller and amounts to less than 5 years (www.ec.europa.eu/eurostat).

In some research, the concept of socio-economic status and impact on health takes into account such aspects as family-based indicators, following on from the argument as using term socio-economic position instead of socio-economic status. According to Max Weber, social position is based on three stratificational dimensions, i.e. class, power and status. In this case "status" should be understood as "access to life chances" [29]. Therefore it is logical to use family background in relation to social determinants of health. The family gives us something what can be simply termed as a "good" or as a "bad" start. Family background influences most areas connected with health, like educational qualifications, low household income and employment chances [30]. It is mainly caused by the individual's decision about their education which are strongly correlated with childhood socio-economic position [31].

Existing studies confirm the crucial role of family background on later health [31]. They note the correlation between family background such as mother's educational attainment and on the respondents' socio-economic position in childhood, to obesity [32] and likelihood of smoking [33]. There is also evidence of a correlation between higher mortality and lower childhood socioeconomic status. This tendency was found in eighteen of 22 countries studied [34]. It was assumed that better family background (higher income, working in a whitecollar job rather than a low-skill occupation) let children achieve a higher level of education, which in turn is easy to relate with an influence on health. Of course, family background associated especially with parent's good financial situation in childhood influences not only the likelihood of higher education being pursued but also the likelihood of a higher quality lifestyle, better health awareness and health behaviour, among other factors. These factors often come from socialization, which in this context means maintaining health standards and being pro-active about one's health. Furthermore, in childhood people develop eating habits, attitudes to sickness and medical institutions which are really difficult to change in adulthood [35]. Our results corresponded with other studies showing that family background has related with SRH. Nevertheless, it shows relation between good health of men and women whose mother works manually or (in case of men) whose mother is unemployed.

As previously mentioned, family background influences educational decisions and consequently occupational status. Subsequently, the type of occupation followed is an important factor influencing the health of both women and men. Most of research compare only working and non-working groups. One of the few studies on the health self-assessment and the types of occupation is the research conducted in US [36]. Gueorguieva et al. (2009). found that odds of poor health increased among service workers and our research showed that men employed in service industries or in a lower rung of the occupational ladder are more likely to report poorer health than men employed in higher-skill occupations [36]. As to women, being employed in a service sector is likely to result in better health. Nevertheless, the service sector was not statically significant in the Self-Rated Health model.

Lower occupational categories were associated with poor self-reported health also in the research conducted in 31 European countries [37]. The same tendency was observed by Case and Deaton who found that employment in manual occupations tends to result in lower SelfRated Health [38]. Not only subjective there is an objective as well as element to this: mortality rates are lower in higher occupational class. It was shown by Smith, Hart, Watt, Hole and Hawthorne in a U.K. analysis that results may be related to many other factors, including nutrition [39]. Research conducted in 2013 in Poland showed that eating habits differed among social classes. The study point to more unhealthy lifestyle in lower class than higher. It is also well know that a manual worker choose more calorific and fatty food [40].

In conclusion, the presented results described social factors which influence Self-Rated Health and everyday functioning when comparing women and men. As the analysis shows, the women's SRH was significantly related to age, socio-economic status, type of occupation and family background. Similar result was observed among men. Everyday functioning measured by WHODAS 2.0 shows the crucial role of socio-economic status according to health, especially level of education which was the largest single contributor to health, for both women and men. As the analysis shows, the level of financial situation during childhood was changing SRH especially among women. To our knowledge, there is no study describing relation between parent's income and Self-Rated Health. For men's health, more important variable was the mother's occupation. What is the most surprising, better men's health was related with mother's unemployment, which is opposite to most research [41]. Generally, parental unemployment was found to have negative consequences for health. Nevertheless, existing studies have mostly focused on unemployment without distinguishing between mothers and fathers. In our research difference between mother's and father's occupation according to health is visible. 


\section{Acknowledgments}

The research leading to these results has received funding from the European Community's Seventh Framework Programme (FP7/2007-2013) under grant agreement number 223071 (COURAGE in Europe), from the Instituto de Salud Carlos III-FIS research grant number PS09/00295 and PS09/01845, and from the Spanish Ministry of Science and Innovation's ACI-Promociona (ACI2009-1010) and Polish Ministry for Science and Higher Education grant for an international co-financed project (number 1277/7PR/ UE/2009/7, 2009-2012). Coordinator of the Polish version of COURAGE in Europe Project was professor Beata Tobiasz-Adamczyk.

\section{References}

1. Burström B., Fredlund P., Self-Rated Health: Is it as good a predictor of subsequent mortality among adults in lower as well as in higher social classes? "Journal of Epidemiology and Community Health” 2001; 55: 836-840.

2. Benjamins M.R., Hummer R.A., Eberstein I.W., Nam C.B., Self-reported health and adult mortality risk: An analysis of cause-specific mortality, "Social Science \& Medicine" 2004; 59: 1297-1306.

3. Pikhart H., Bobak M., Siegrist J., Pajak A., Rywik S., Kyshegyi J., Gostautas A., Skodova Z., Marmot M., Psychosocial work characteristics and Self-Rated Health in four post-communist countries, "Journal of Epidemiology and Community Health” 2001; 55: 624-630.

4. Lee H.-W., Song M., Yang J.J., Kang D., Determinants of poor Self-Rated Health in Korean adults with diabetes, "Journal of Preventive Medicine and Public Health" 2015; 48: $287-300$.

5. Eriksson I., Undén A.L., Elofsson S., Self-Rated Health. Comparisons between three different measures. Results from a population study, "International Journal of Epidemiology" 2001; 30: 326-333.

6. Mewton L., Andrews G., Poor Self-Rated Health and its associations with somatisation in two Australian national surveys, "BMJ Open" 2013; 3: e002965.

7. DeSalvo K.B., Bloser N., Reynolds K., He J., Muntner P., Mortality prediction with a single general Self-Rated Health question, “J. Gen. Intern. Med.” 2006; 21: 267-275.

8. Üstün by T., Kostanjsek N., Chatterji S., Rehm J., Measuring Health and Disability Manual for WHODAS Disability Assessment Schedule WHODAS 2.0, WHO Library Cataloguing-in-Publication Data Measuring Health and Disability: Manual for WHO Disability Assessment Schedule (WHODAS 2.0).

9. Hoeymans N., Feskens E.J.M., van den Bos G.A.M., Kromhout D., Measuring functional status: Cross-sectional and longitudinal associations between performance and self-report (Zutphen Elderly Study 1990-1993), "Journal of Clinical Epidemiology” 1996; 49: 1103-1110.

10. Kaleta D., Makowiec-Dąbrowska T., Jegier A., Employment Status and Self-Rated Health, "International Journal of Occupational Medicine and Environmental Health" 2008; 21: 227-236.
11. Kunst A.E., Bos V., Lahelma E., Bartley M., Lissau I., Regidor E., Mielck A., Cardano M., Dalstra J.A., Geurts J.J., Helmert U., Lennartsson C., Ramm J., Spadea T., Stronegger W.J., Mackenbach J.P., Trends in socio-economic inequalities in self-assessed health in 10 European countries, "International Journal of Epidemiology" 2005; 34: 295-305.

12. Szaflarski M., Cubbins L.A., Self-Reported Health in Poland and the United States: A comparative analysis of demographic, family and socio-economic influences, "Health: An Interdisciplinary Journal for the Social Study of Health, Illness and Medicine" 2004; 8: 5-31.

13. Leonardi M., Chatterji S., Koskinen S., Ayuso-Mateos J.L., Haro J.M., Frisoni G., Frattura L., Martinuzzi A., Tobiasz-Adamczyk B., Gmurek M., Serrano R., Finocchiaro C., Determinants of health and disability in ageing population: The COURAGE in Europe Project (Collaborative Research on Ageing in Europe), "Clinical Psychology and Psychotheraphy” 2014; 21: 193-198.

14. Kimber M., Rehm J., Ferro M.A., Georgiades K., SerranoBlanco A., Roca M., Measurement invariance of the WHO$D A S 2.0$ in a population-based sample of youth, "PLoS One" 2015; 10: e 0142385 .

15. Noh J.-W., Kim J., Park J., Kim H., Kwon Y.D., Gender difference in relationship between health-related quality of life and work status, "PLoS One" 2015; 10: e0143579.

16. Marmot M., Social determinants of health inequalities, "Lancet" 2005; 365: 1099-1104.

17. Hosseinpoor A.R., Stewart Williams J., Amin A., Araujo de Carvalho I., Beard J., Boerma T., Kowal P., Naidoo N., Chatterji S., Social determinants of Self-Reported Health in women and men: Understanding the role of gender in population health, "PLoS One" 2012; 7: e34799.

18. Kenisha S., Jonsson R., Adjei GÖ N., Marriage, work and health: A cross national comparative study of the impact of welfare regimes on gender-specific working hours and self-assessed health, "DRAFT" 2015.

19. Mackenbach J.P., Stirbu I., Roskam A.-J.R., Schaap M.M., Menvielle G., Leinsalu M., Kunst A.E., Socio-economic Inequalities in Health in 22 European Countries, "The New England Journal of Medicine" 2008; 358: 2468-2481.

20. Idler E.L., Discussion: Gender differences in Self-Rated Health, in mortality, and in the relationship between the two, "Gerontologist" 2003; 43: 372-375.

21. Tobiasz-Adamczyk B., Brzyski P., Factors determining changes in Self-Rated Health in the Polish communitydwelling elderly, "Central European Journal of Public Health" 2005; 13: 117-124.

22. Andersen F.K., Christensen K., Frederiksen H., Self-Rated Health and age: A cross-sectional and longitudinal study of 11,000 Danes aged 45-102, "Scandinavian Journal of Public Health" 2007; 35: 164-171.

23. Robards J., Evandrou M., Falkingham J., Vlachantoni A., Marital status, health and mortality, "Maturitas" 2012; 73: 295-299.

24. Kolip P., The association between gender, family status and mortality, "Journal of Public Health (Bangkok)" 2005; 13: 309-312.

25. Probst C., Roerecke M., Behrendt S., Rehm J., Gender differences in socio-economic inequality of alcohol-attributable 
mortality: A systematic review and meta-analysis, "Drug and Alcohol Review" 2015; 34: 267-277.

26. Mackenbach J.P., Kulhánová I., Bopp M., Borrell C., Deboosere P., Kovács K., Caspar W., Looman N., Leinsalu M., Mäkelä P., Martikainen P., Menvielle G., RodríguezSanz M., Rychtaříková J., de Gelder R., Inequalities in alcohol-related mortality in 17 European countries: A retrospective analysis of mortality registers, "PLos Med" 2015; 12: e1001909.

27. Dowd J.B., Zajacova A., Does the predictive power of SelfRated Health for subsequent mortality risk vary by socioeconomic status in the US? "International Journal of Epidemiology" 2007; 36: 1214-1221.

28. Alvarez-Galvez J., Rodero-Cosano M.L., Motrico E., Salinas-Perez J.A., Garcia-Alonso C., Salvador-Carulla L., The impact of socio-economic status on Self-Rated Health: Study of 29 countries using European social surveys (2002-2008), "International Journal of Environmental Research and Public Health" 2013; 10: 747-761.

29. Mishra G.D., Ball K., Dobson A.J., Byles J.E., Warner-Smith P., Which aspects of socio-economic status are related to health in mid-aged and older women? "International Journal of Behavioral Medicine” 2002; 9: 263-285.

30. Mckenzie S.K., Carter K.N., Blakely T., Ivory V., Effects of childhood socio-economic position on subjective health and health behaviours in adulthood: How much is mediated by adult socio-economic position? "BMC Public Health" 2011; 11: 269.

31. Mazzonna F., The long-lasting effects of family background: A European cross-country comparison, "Economics of Educational Review" 2014; 40: 25-42.

32. Zheng H., Tumin D., Variation in the effects of family background and birth region on adult obesity: Results of a prospective cohort study of a Great Depression-era American cohort, "BMC Public Health" 2015; 15: 535.

33. Power C., Graham H., Due P., Hallqvist J., Joung I.., Kuh D, Lynch J., The contribution of childhood and adult socioeconomic position to adult obesity and smoking behaviour:
An international comparison, "International Journal of Epidemiology" 2005; 34: 335-344.

34. Galobardes B., Lynch J.W., Davey Smith G., Childhood socio-economic circumstances and cause-specific mortality in adulthood: Systematic review and interpretation, "Epidemiology Review" 2004; 26: 7-21.

35. Umeda M., Oshio T., Fujii M., The impact of the experience of childhood poverty on adult health-risk behaviors in Japan: A mediation analysis, "International Journal for Equity in Health" 2015; 14: 145.

36. Gueorguieva R., Sindelar J.L., Falba T.A., Fletcher J.M., Keenan P., Wu R., Gallo W.T., The impact of occupation on Self-Rated Health: Cross-sectional and longitudinal evidence from the health and retirement survey, "The Journals of Gerontology, Series B: Psychological Sciences and Social Sciences" 2009; 64: 118-124.

37. Schutte S., Chastang J.-F., Parent-Thirion A., Vermeylen G., Niedhammer I., Association between socio-demographic, psychosocial, material and occupational factors and self-reported health among workers in Europe, "Journal of Public Health (Bangkok)" 2014; 36: 194-204.

38. Case A., Deaton A., Broken Down by Work and Sex: How Our Health Declines. Analyses in the Economics of Aging 2005; http://www.nber.org/papers/w9821 (accessed: 17.01.2018).

39. Smith G.D., Hart C., Watt G., Hole D., Hawthorne V., Individual social class, area-based deprivation, cardiovascular disease risk factors, and mortality: The Renfrew and Paisley Study, "Journal of Epidemiology and Community Health" 1998; 52: 399-405.

40. Irala-Estévez J.D., Groth M., Johansson L., Oltersdorf U., Prättälä R., Martínez-González M.A., A systematic review of socio-economic differences in food habits in Europe: Consumption of fruit and vegetables, "The European Journal of Clinical Nutrition" 2000; 54: 706-714.

41. Sleskova M., Salonna F., Geckova A.M., Nagyova I., Stewart R.E., van Dijk J.P., Groothoff J.W., Does parental unemployment affect adolescents' health? "Journal of Adolescent Health" 2006; 38: 527-535. 